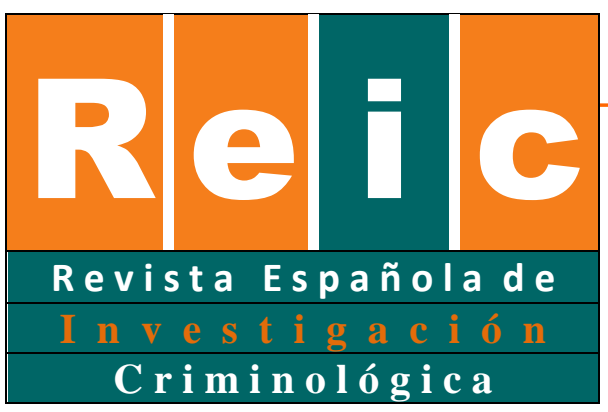

Redondo

\title{
Editorial
}

Santiago Redondo Illescas

Editor-jefe REIC

Universidad de Barcelona

\section{La REIC, faro editorial de la Criminología española hacia el futuro}

Con la publicación de su número 16 (correspondiente a 2018), la Revista Española de Investigación Criminológica (REIC) tecnifica e internacionaliza su edición. Así, en efecto, el nuevo número de la REIC encabezado por este Editorial aparece ya en una reconocida plataforma internacional de revistas científicas. Hasta aquí la REIC había efectuado una larga y rica andadura en plataformas editoriales propias. Pero el objetivo principal de una publicación científica periódica es, por su propia naturaleza, lograr la mayor proyección y difusión posible de los artículos que edita. De ahí que desde la Sociedad Española de Investigación Criminológica (SEIC) se haya dado el paso de internacionalizar su revista en la mayor medida posible. El momento ya estaba maduro para ello. La REIC ha editado ininterrumpidamente, entre 2003 y 2017, 15 anuarios con un monto total de 118 trabajos publicados (incluyendo 81 artículos, 8 monografías, 17 recensiones de libros, 6 notas de investigación y 12 Editoriales), sobre prácticamente todas las temáticas que son objeto del análisis criminológico.

El número 16 que ahora se abre, en la plataforma Open Journal System (OJS), es heredero legítimo de toda nuestra trayectoria editora precedente. Por ello nace ya sazonado, con un número de artículos superior a los que habían inaugurado nuestros números anteriores. Esto no es casual. Si a estas alturas del año hay un mayor número de artículos ya publicados, es porque en la REIC se han recibido más manuscritos para su publicación. Y si más autores deciden enviar sus trabajos a la REIC, es porque nuestra revista se ha convertido en una publicación criminológica de gran interés y prestigio. Por

Revista Española de Investigación Criminológica 
todo esto, debemos estar y estamos de enhorabuena. La investigación criminológica española ha progresado de forma decisiva durante las últimas décadas, y la REIC es un indicador fidedigno de este progreso.

Así pues, el esfuerzo colectivo de investigación que se ha realizado, al que han contribuido muchos investigadores, equipos de investigación y universidades, debe hacernos sentir enormemente orgullosos. Pero este orgullo legítimo no debe impedir la identificación de nuevos horizontes y retos pendientes. La investigación científica es siempre efímera y mejorable. Los resultados de investigación son, por definición, provisionales y requeridos por ello de nuevos y más completos análisis, metodologías y perspectivas conceptuales. Y las temáticas que hemos analizado en el pasado se abrirán poco a poco a nuevos campos y problemas de investigación, que las propias realidades criminales irán sugiriendo. Visto todo esto y, más aún, conociendo los avances de la propia disciplina criminológica y la incorporación a ella de nuevas criminólogas y criminólogos que llegan con ilusiones y formación renovadas, el futuro de la REIC será, sin duda, emocionante y extraordinario.

Como Editor cesante de la REIC, permítaseme para finalizar un comentario de cariz más personal. He desempeñado el rol de Editor-Jefe de la REIC durante el bienio 2016-2018, para el que fui designado por la Asamblea de la SEIC a propuesta de su anterior Junta directiva. Ha sido un periodo de trabajo muy estimulante a la par que muy intenso. Cualquier lector que haya enviado un manuscrito a una revista científica, o que haya sido revisor de alguna revista (entre ellas, la propia REIC), puede fácilmente conocer el intrincado proceso de revisión científica por el que suele pasar un manuscrito hasta que, en el mejor de los casos, es aceptado para publicación. Para fortuna mía, durante este periodo he podido contar con la hábil y esforzada colaboración de Ágata Mangot. Le agradezco a ella su dedicación y buen hacer en la REIC, incluida la puesta en marcha de la nueva plataforma, todo lo cual ha contribuido a hacer de la REIC una mejor revista. Durante esta etapa, también ha sido pieza fundamental de la REIC, aunque en la sombra, la profesora Laura Vozmediano. Son infinitas las horas que ha sustraído de su propio tiempo académico para dedicarlas generosa y entusiastamente a la REIC. Es mérito suyo la localización y gestión de la nueva plataforma de la revista y, en coordinación con 
Ágata, la migración a aquella de toda la información científica y administrativa acumulada con anterioridad.

Enfrentarse a la valoración de nuevos manuscritos científicos y a la decisión final de aceptarlos o rechazarlos es, como fácilmente podrá colegirse, una tarea delicada y de gran responsabilidad. La buena noticia a este respecto es que el Editor-Jefe de la REIC cuenta para ello con la ayuda cercana y erudita del Comité editorial, en el que se integran los Editores asociados (quienes anteriormente fueron Editores-Jefe de la REIC). Es decir, he sido muy afortunado al contar con la ayuda necesaria para muchas de las decisiones que debía adoptar de, nada menos, que los profesores Juan José Medina, Vicente Garrido, César San Juan y Josep Cid.

Pero, sin duda, el pilar fundamental que sustenta una revista científica son todos aquellos autores que confían en ella y deciden someterle sus contribuciones. Sin muchos autores y equipos de investigación que hubieran decidido confiar en nuestra revista, la REIC no habría podido existir, tener continuidad y publicar todos los estudios y monografías que ha publicado hasta ahora. Mas si los autores constituyen, podríamos decir, la cara visible de la moneda de cualquier publicación científica, igual de cruciales resultan los integrantes de la cruz o el reverso de cada trabajo publicado: los revisores. Sin sus revisores expertos la REIC tampoco podría haber existido. Los autores, si su trabajo es aceptado y se publica, obtienen la mayor recompensa académica, que es justamente la publicación formal y prestigiosa de sus resultados de investigación. En cambio, los revisores, tan a menudo denostados, efectúan un trabajo anónimo, generoso y de recompensa incierta, más allá de la propia satisfacción de contribuir con honestidad a realzar la calidad de lo que otros publican. Por todo ello, autores y revisores merecen, como sujetos principales de la producción científica, nuestro mayor reconocimiento y gratitud.

A mediados de 2018 la Asamblea de la SEIC designará un nuevo Editor o Editora Jefe de la REIC, cuyo reto será sin duda continuar haciendo de la REIC un faro editorial de la Criminología española en dirección al futuro. 